\title{
VESICULAR ARBUSCULAR MYCORRHIZA IN AGRO-FORESTRY SYSTEMS OF COFFEE, CACAO AND PEPPER
}

\author{
JB Palipane \\ Department of Export Agriculture, Nillambe
}

Kandyan forest gardens are typical examples of mixed cropping systems of Sri Lanka. These are considered as the older agro-forestry systems. They contain a wide range of perennial crop species, which survive mostly without inorganic fertilizer. The Delpitiya Mixed Cropping Model (DELMIX) was planted in 1973 by using eroded tea land. DELMIX receives all the recommended inputs and cultural practices such as fertilizing, weeding, training and pruning. This study was conducted in the above agro-forestry systems to estimate the mycorrhizal population of coffee, cacao, pepper and to determine the effects and association of mycorrhiza on these plant species

Vesicular arbuscular mycorrhizae (YAM) were found to be associated with vigorously growing coffee, cacao, and pepper plants in tie unfertilized agro-forestry systems. Artificially inoculated coffee and cacao seedlings had a significantly higher growth rate than that of uninoculated seedlings. Inoculation of VAM in pepper nursery was found to enhance growth and produce healthy cuttings. There was no significant difference between the growth of artificially inoculated coffee plants grown in the field with application of fertilizer. Unhealthy stunted plants were observed in the uninoculated coffee grown without application of fertilizer.

The population of VAM spores was compared in the rhizosphere of coffee, cacao and pepper in the DELMIX and other agro-forestry systems. These results indicated that unfertilized agroforestry systems contain significanty higher number of VAM spores. Hence, it can be concluded that VAM association had a better beneficial impact in the agro-forestry systems of coffee, cacao and pepper. 